\title{
NONLINEAR MODEL OF AN ADDITIONAL CONCRETE HEAD AND ITS COMPARISON WITH LONG-TERM MEASUREMENTS
}

Jan NOVÁČEK ${ }^{*}$, Miloš ZICH ${ }^{1}$, Michal HASA ${ }^{1}$

\begin{abstract}
An additional concrete head or drop panels are not common solutions for strengthening flat slabs and have not yet been an adequately studied solution in the field of laboratory research. The investigation of drop panels in a laboratory is quite complicated, so that an examination directly at a construction site could be a better solution. Long-term measurement sensors were installed inside a concrete drop panel, which is on the bottom surface of a flat slab. Gauging was performed during various loading situations, including the loading of heavy machines, the ambient temperature load, and a uniformly distributed load. Results from the measurements are given in comparison with analytical models, which have been studied with respect to the influence of shrinkage and the bond-slip behaviour of a reinforcement.
\end{abstract}

\section{Address}

1 Brno University of Technology, Faculty of Civil Engineering, Dept. of Concrete and Masonry Structures, Czech Republic

* Corresponding author: jan.novacek@vutbr.cz

\section{Key words}

- Concrete,

- Punching,

- Strengthening,

- Nonlinear models,

- Gauging.

\section{INTRODUCTION}

The verification of nonlinear analytical models with respect to experiments on concrete slabs has been studied by numerous authors, e.g. (Belletti et al, 2015). As part of long-term research on the strengthening of structures against punching shear in the form of an additional concrete head, a study was published (Nováček and Zich, 2016). Models based on material and geometric non-linearity have been developed for studying the efficiency of increasing the shear capacity in punching. The effect of surface roughness, interlocking reinforcements, and the effect of the length of top slab rebars has also been studied. In its first part this continuing article introduces the effect of rheological phenomena and the bond-slip relationship along the reinforcement. Based on a comprehensive study, it was possible to apply the knowledge acquired for the design of the strengthening of the actual structure, which was subsequently followed by long-term measurements. The analytical numerical models were developed using the ATENA 3D v5 software.

\section{CLARIFICATION OF ANALYTICAL MODELS}

\subsection{Influence of rheology}

The casting of a new concrete element in contact with older concrete means it is necessary to take into account the rheological phenomena occurring in the new part in its interaction with the already hardened concrete. Above all, consideration of shrinkage must be verified, i.e., the autogenous shrinkage that develops while concrete is hardening, especially in the first days after concreting, and the drying shrinkage, which predominates later. The analysis of the shrinkage is based on a model of the slab with an additional concrete head (sometimes referred as an additional drop panel), where the contact surface is considered to be rough in the meaning of Model Code 2010 and the $\varnothing 10 / 150 / 150 \mathrm{~mm}$ reinforcement crossing interface, Figs. 1 and 2. The model is called PG-11-E within the meaning of a previous study (Nováček and Zich, 2016). The geometric and material inputs for the analytical models are mentioned in Tab. 1, where $d$ is the effective depth; $\varnothing$ is the diameter of the rebar in perpendicular directions; $\rho_{l}$ is the reinforcement ratio; $d_{g}$ is the aggregate size; $f_{c}$ is the compressive cylinder strength of the concrete; $f_{c t}$ is the tensile concrete strength; 
Tab. 1 Input data for the analytical model

\begin{tabular}{c|c|c|c|c|c|c|c|c|c|c|c}
\hline sample & $\begin{array}{c}\text { dimension } \\
{[\mathrm{mm}]}\end{array}$ & $\begin{array}{c}d \\
{[\mathrm{~mm}]}\end{array}$ & $\begin{array}{c}\varnothing \\
{[\mathrm{mm}]}\end{array}$ & $\begin{array}{c}\text { spacing } \\
{[\mathrm{mm}]}\end{array}$ & $\begin{array}{c}\rho_{l} \\
{[\%]}\end{array}$ & $\begin{array}{c}d_{g} \\
{[\mathrm{~mm}]}\end{array}$ & $\begin{array}{c}f_{c} \\
{[\mathrm{MPa}]}\end{array}$ & $\begin{array}{c}f_{c t} \\
{[\mathrm{MPa}]}\end{array}$ & $\begin{array}{c}E_{c} \\
{[\mathrm{GPa}]}\end{array}$ & $\begin{array}{c}f_{y} \\
{[\mathrm{MPa}]}\end{array}$ & $\begin{array}{c}f_{u} \\
{[\mathrm{MPa}]}\end{array}$ \\
\hline PG-11 & $3000 / 3000 / 250$ & 210 & $16 / 18$ & 145 & 0.75 & 16 & 31.5 & 2.5 & 31.0 & 570 & 586 \\
\hline
\end{tabular}

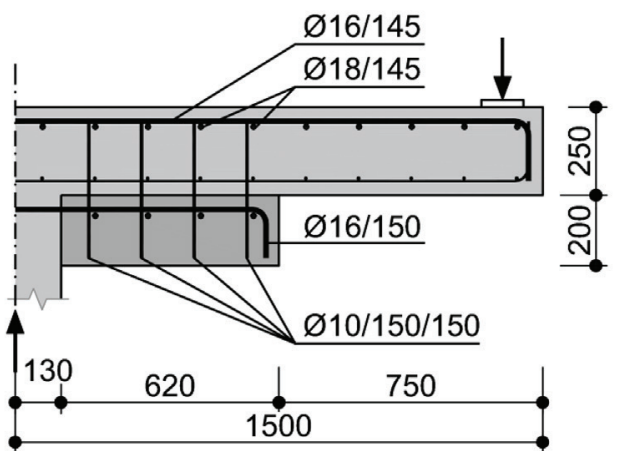

Fig. 1 Scheme of the additional concrete head, including its reinforcement

$E_{c}$ is the modulus of elasticity; $f_{y}$ is the yield strength of the reinforcement; and $f_{u}$ is the ultimate strength of the reinforcement.

The main objective is to study the effect of the shrinkage on the analytical models and not to study the shrinkage models. Therefore, only one approach has been adopted, which is according to EN 1992-1-1, Annex B. Shrinkage for the first 10 years was considered, according to the model used; the shrinkage at this age would be approximately $95 \%$ of the total shrinkage. The development of the relative strain from shrinkage is shown in Fig. 3.

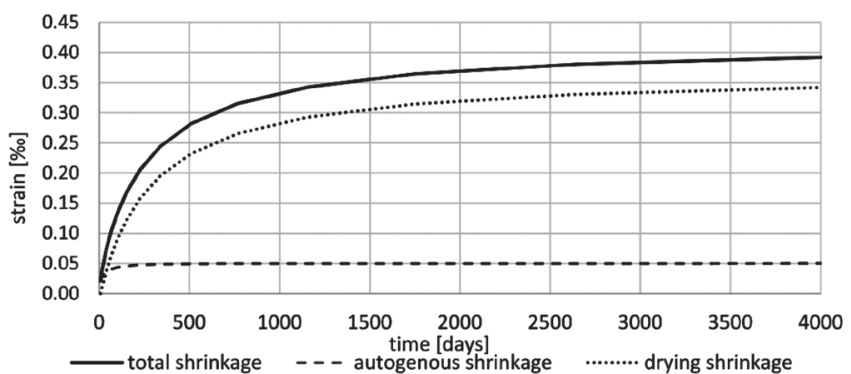

Fig. 3 Development of the shrinkage applied to the additional head (concrete C35/45)

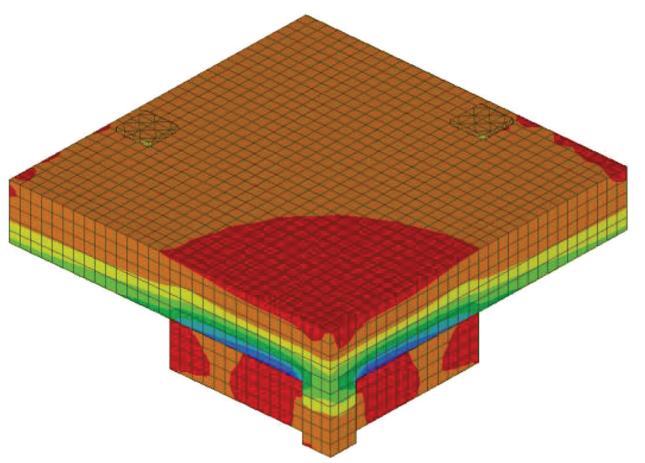

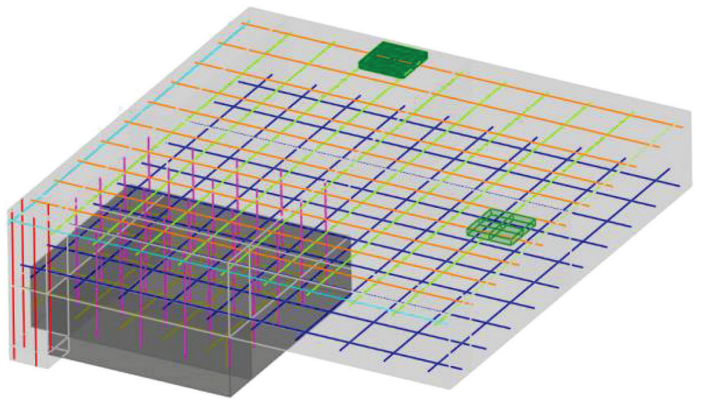

Fig. 2 View of the analytical model with an additional head

The shrinkage function described was applied to analyse the rheological phenomena models that were formed for the static analysis, which was transferred to the creep task. The Atena software uses a cross-sectional approach, which means that the analysis builds upon the creep and shrinkage behavior of the whole cross section rather than the behavior of the individual material points only. The discretized structure is solved in several time steps; for detailed information, see the Theory manual (Červenka et al., 2018). The intended progress of the creep is also governed by the EN 1992-1-1 approach. The input parameters were chosen to be $70 \%$ ambient humidity, $42.5 \mathrm{R}$ cement, a curing time of 7 days, and quartz as the aggregate. The model was only loaded for the development of shrinkage and creep without any static load, so that the results were not influenced by other factors.

Shrinkage, i.e., shrinkage and creep caused by shrinkage, exerts tension on the elements only when it is somehow restrained. The boundary condition for the additional head is defined by its contact with the older concrete. Tensile stresses are expected to occur in the new head. On the other hand, the compression is expected in the original concrete slab.

Fig. 4 shows the minimum principal stress in concrete, which reaches values of up to $-2.7 \mathrm{MPa}$ in the existing slab. The positive signed values for the maximal principal stress with the same absolute magnitude as the minimal principal stress are in the new head near the contact surface, see Fig. 5.

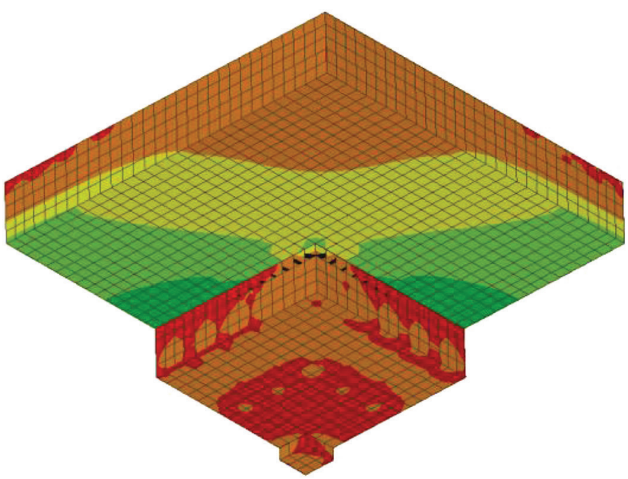

$-0.8$

$-1.2$

$-1.6$

$-1.9$

$-2.3$

$-2.7$

[MPa]

Fig. 4 Minimal principal stress on the model loaded only by shrinkage 10 years after casting 

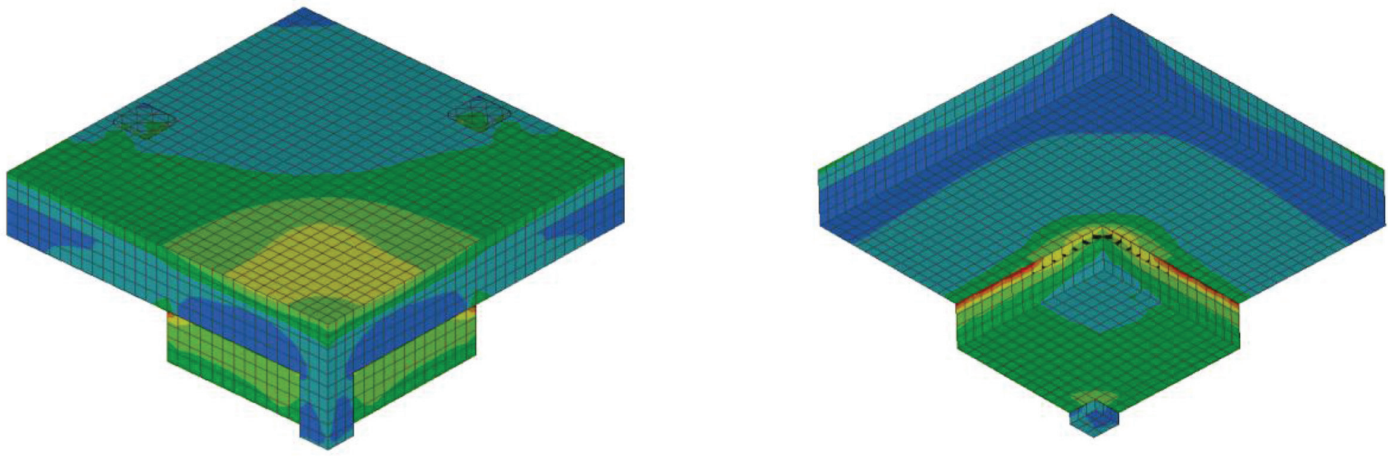

Fig. 5 Maximal principal stress on the model loaded only by shrinkage 10 years after casting
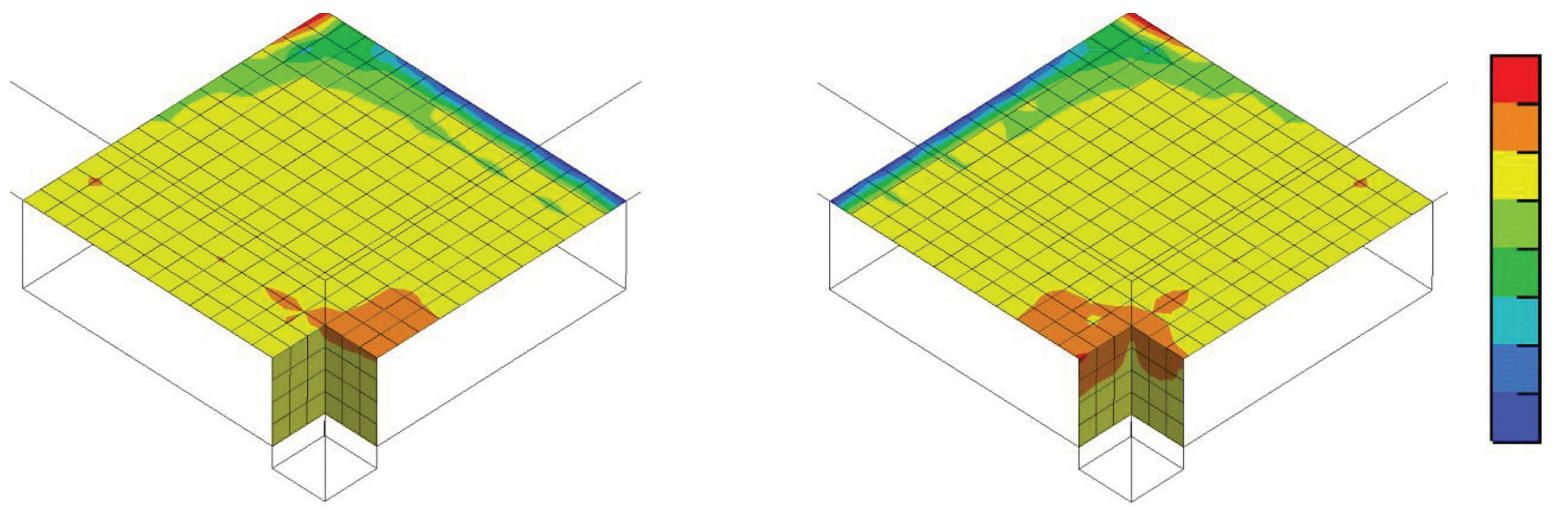

Fig. 6 Shear stress for the perpendicular direction on the contact plane 10 years after casting
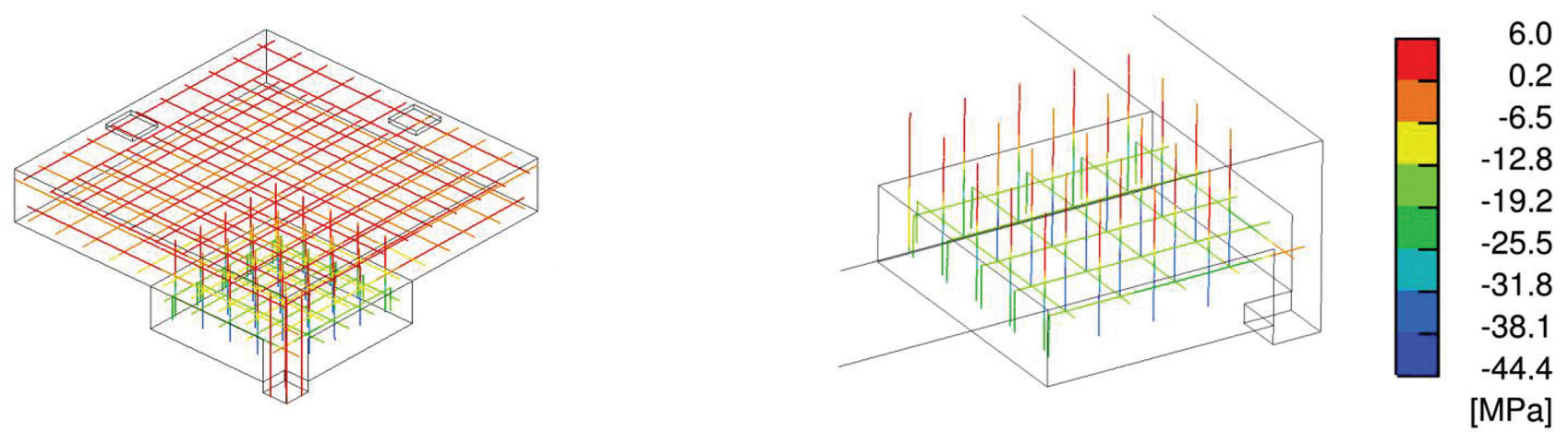

Fig. 7 Reinforcement stress 10 years after casting

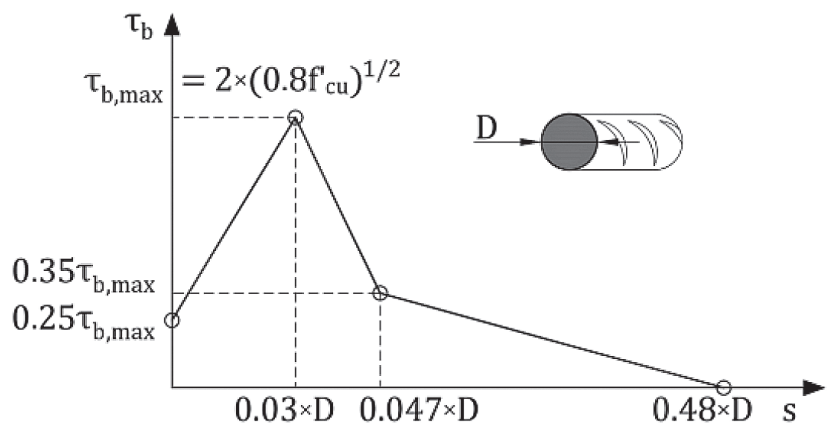

Fig. 8 Function of a bond-slip relationship for a good bond condition
There is a noticeable drop in stress caused by exceeding the cohesion in the contact layer at the outer corner of the head. This phenomenon also illustrates the movement of the shear stress areas on the contact elements towards the centre of the head, Fig. 6.

From the perspective of the tension in the reinforcement in the existing slab, there is only a slight increase in the tension in the top bending reinforcement (6 MPa), Fig. 7. This stress is caused by the compression in the concrete slab on the bottom fibres. It is important to note that the interlocking reinforcement is not loaded by shrinkage. In the area of the interlocking reinforcement, the stress does not exceed the cohesion; thus the reinforcement is not stressed by the shrinkage.

\subsection{Effect of the bond-slip}

The reinforcement bond model is defined by the bond-slip relationship (Bigaj, 1999). The dependence of the bond strength $\tau_{b}$ on the 


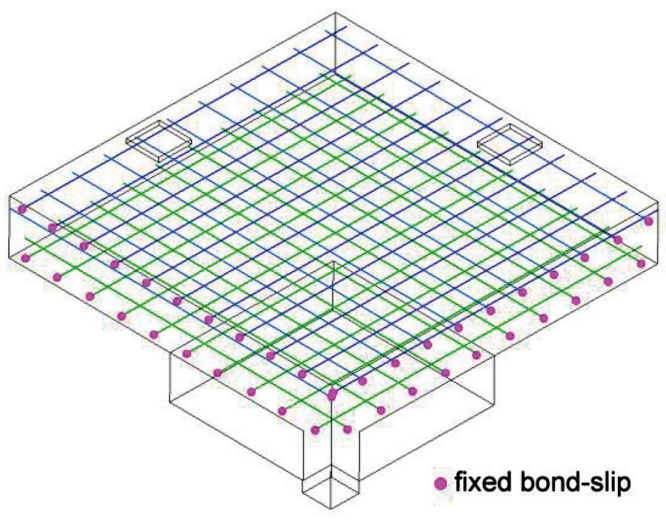

Fig. 9 Bond-slip boundary conditions for the horizontal reinforcement in the slab

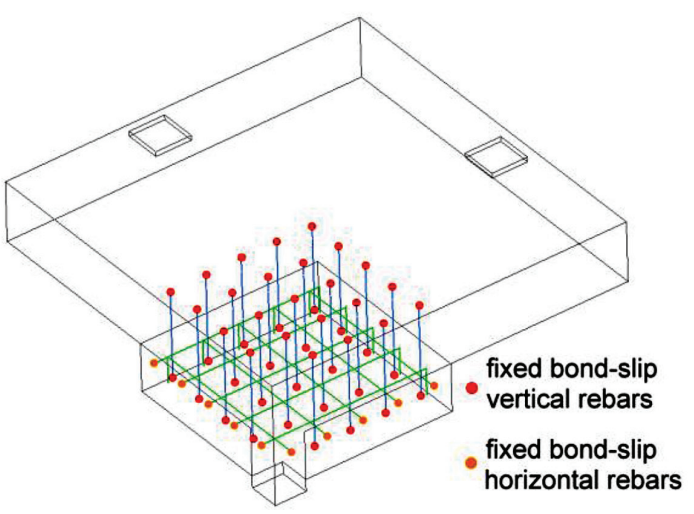

Fig. 10 Bond-slip boundary conditions for the reinforcement in the head

Tab. 2 Results from the analytical models with additional head and contact elements at the interface

\begin{tabular}{c|c|c|c|c|c|c|c|c}
\hline Variant & $\begin{array}{c}\text { Type of } \\
\text { interface }\end{array}$ & $\begin{array}{c}\text { Cohesion } \\
{[\mathrm{MPa}]}\end{array}$ & Friction coeff. & $\begin{array}{c}V_{\text {NLFEM }} \\
{[\mathrm{kN}]}\end{array}$ & $\begin{array}{c}\sigma_{s, \text { column }} \\
{[\mathrm{MPa}]}\end{array}$ & $\begin{array}{c}\sigma_{\text {s,middle }} \\
{[\mathrm{MPa}]}\end{array}$ & $\begin{array}{c}w_{\text {column }} \\
{[\mathrm{mm}]}\end{array}$ & $\begin{array}{c}w_{\text {middle }} \\
{[\mathrm{mm}]}\end{array}$ \\
\hline PG-11-D & Smooth & 0.5 & 0.5 & 1815 & 600 & 400 & 24.2 & 14.5 \\
\hline PG-11-E & Rough & 2.0 & 0.85 & 1978 & 587 & 480 & 26.2 & 15.8 \\
\hline PG-11-F & Very rough & 3.0 & 1.2 & 2132 & 590 & 490 & 23.9 & 15.0 \\
\hline PG-11-D* & Smooth & 0.5 & 0.5 & 1851 & 578 & 419 & 28.0 & 16.5 \\
\hline PG-11-E* & Rough & 2.0 & 0.85 & 1978 & 578 & 410 & 28.7 & 17.7 \\
\hline PG-11-F* & Very rough & 3.0 & 1.2 & 2100 & 576 & 415 & 23.6 & 14.3 \\
\hline
\end{tabular}

slip is approximated by a multilinear function. The function used is shown in Fig. 8, where $D$ refers to the diameter of the reinforcement and $f^{\prime}$ ' to the cube compressive strength of concrete.

The boundary conditions for the discrete reinforcement elements are shown in Figs. 9 and 10. Shear double-headed studs are considered as an additional vertical reinforcement, which could be treated in the model as elements with fixed ends for the bond-slip behaviour (Pryl and Červenka, 2018). An appropriate anchor plate could provide correct detail of the post-installed reinforcement on the top surface of the slab.

Tab. 2 states the results of models with the additional concrete head for different types of interfaces. The models with the effect of shrinkage in the form of the initial strain and the bond-slip behaviour of the reinforcement have an asterisk next to them. The models without an asterisk ignore these effects. Comparing them with models where these two phenomena are ignored, the absolute bearing capacity differs by a few percentage points. The reinforcement stress $\sigma_{\text {scolum }}$ (stress in the top bending reinforcement at the location of the column) and $\sigma_{\text {s,middle }}$ (stress in the top bending reinforcement at the edge of the additional concrete head) is slightly lower compared to the simple models. At the same time a greater amount of deflection $w_{\text {column }}$ (at the location of the column) and $w_{\text {middle }}$ (at the edge of the additional concrete head) is achieved for the smooth and rough surfaces. For the very rough interface, the deformation is about at the same level at the location of the column and at the point of the head (a difference of $0.7 \mathrm{~mm}$ ). The governing mode of failure is punching shear for all the PG-11 models. The models studied show that the effects of the shrinkage and bond-slip do not have a significant influence on the absolute load-bearing capacity in punching $\left(V_{\text {NLFEM }}\right)$ or the deformation behaviour of the structure. In a simplified case, these effects can be ignored.

\section{MEASURING THE ACTUAL STRENGTHENED STRUCTURE}

A monolithic concrete structure with flat slabs built in 2009 was rehabilitated due to a change in the utilization of the roof slab. It was originally designed as a parking garage; then its purpose was changed to a green roof area with a high level of a superimposed permanent load. In this kind of case, it is usually not possible to strengthen the structure only by a post-installed shear steel reinforcement (Polak and $\mathrm{Bu}, 2013$ ) or in the form of an FRP reinforcement (Esfahani et al., 2009). It was therefore necessary to choose a robust solution that would significantly increase the load-bearing capacity of the structure in the punching shear. An alternative solution was to change the static scheme, so that the structure would not be prone to punching failure (additional girders, etc.).

The scheme of the existing structure with the designed strengthening by an additional concrete head is shown in Fig. 11. Drop panels were already on the existing columns. The susceptibility of the structure to failure was determined at the end of the walls at axes 10 and 11. In addition to the concrete head, the design was supplemented by a wall extension to reduce the roof span. Strengthening against punching shear at the current drop panels was not necessary, because the slab was supplemented with internal double-headed shear studs which strongly increased the load-bearing capacity.

The strengthening was carried out on a pair of concrete heads symmetrical to each other; one of them was chosen for the installation of the measurement sensors. The concrete head at axis $\mathrm{C} / 10$ was selected, because it is exposed to a larger load area. The measurement sensors were installed in the reinforcement layout before the concrete was cast.

At the level of the bottom reinforcement, vibrating wire strain gauges were positioned in perpendicular directions. They also permit- 
PLAN

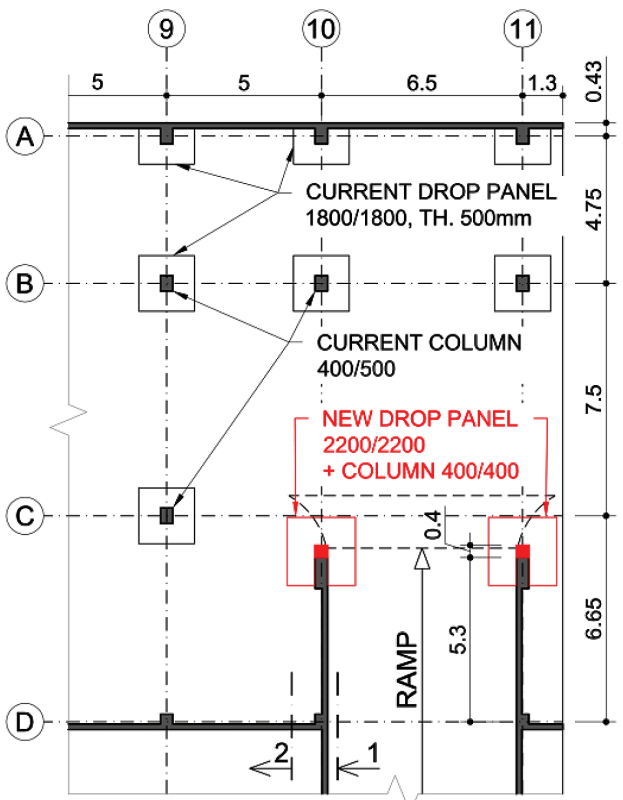

\section{SECTION 1}

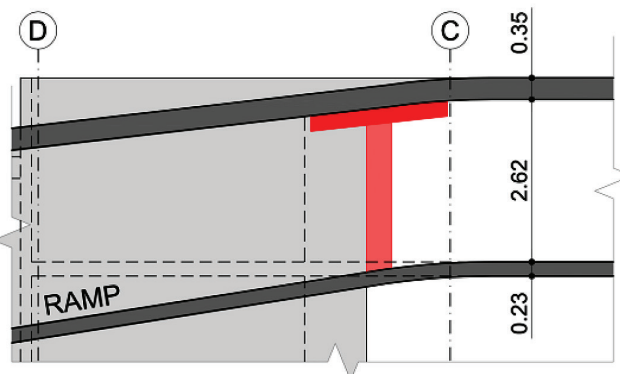

SECTION 2

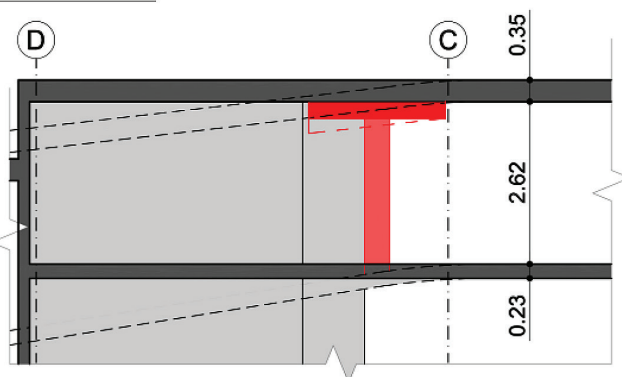

Fig. 11 Scheme of the current structure with the designed rehabilitation solution

ted gauging the temperature of the concrete structure. Three threaded rods were equipped with resistance strain gauges. Pairs of sensors were placed on opposite sides of each rod to eliminate the effect of the bending. Washers with nuts were placed at the ends of the rods for their proper anchoring. The rods were designed as an interlocking reinforcement. The plan view of the individual strain gauges, including the definition of their position to the existing structure, is shown in Fig. 12. A view of the vibrating wire strain gauges and resistance strain gauges can be seen in Fig. 13 and Fig. 14. The measurement sensors on the resistance strain gauges were considered complementary to the wire strain gauges, which would have a better predictive value for the structural behaviour in this case.

The head was cast at the same time as the column in May 2016, see Fig. 15. Four pouring and venting holes were drilled in the current slab; one hole was placed in the wall extension. Good contact with no caverns at the joint on the bottom surface of the current slab was ensured by the self-compacting concrete. The type of concrete was

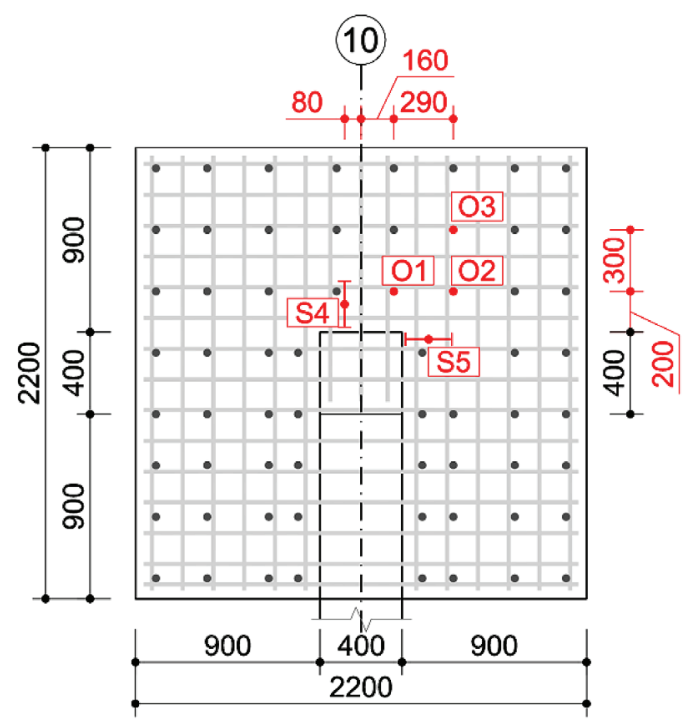

Fig. 12 Plan view of the vibrating wire strain ganges (S) and resistance strain gauges $(O)$ inside the additional concrete head
$\mathrm{C} 35 / 45 \mathrm{XC} 4, \mathrm{XD} 2$ with a maximum aggregate size of $16 \mathrm{~mm}$ and a consistency class of SF1 according to the slump-flow test. Two concrete cube samples $(150 \times 150 \mathrm{~mm})$ were taken during the casting of the element for a subsequent strength test of the concrete. Laboratory tests after 28 days resulted in compressive strengths of $60.7 \mathrm{MPa}$ and $58.8 \mathrm{MPa}$

Core boring was carried out in the existing slab at the position of the additional head, and the compressive strength was tested on the extracted sample. The test sample had dimensions of $100 \mathrm{~mm}$ in diameter and was $100 \mathrm{~mm}$ thick. The sample failed under force when the compressive stress reached 55.7 MPa. In the vicinity of the head, two other samples were drilled and the tests showed compressive concrete strength results of $48.4 \mathrm{MPa}$ and $50.8 \mathrm{MPa}$.

Due to the dimensions of the samples, the concrete strengths obtained were cube concrete strengths. In the case of a classification according to EN 1990 of the Annex D7.2 with an unknown variation coefficient and considering the normal distribution, then the charac-

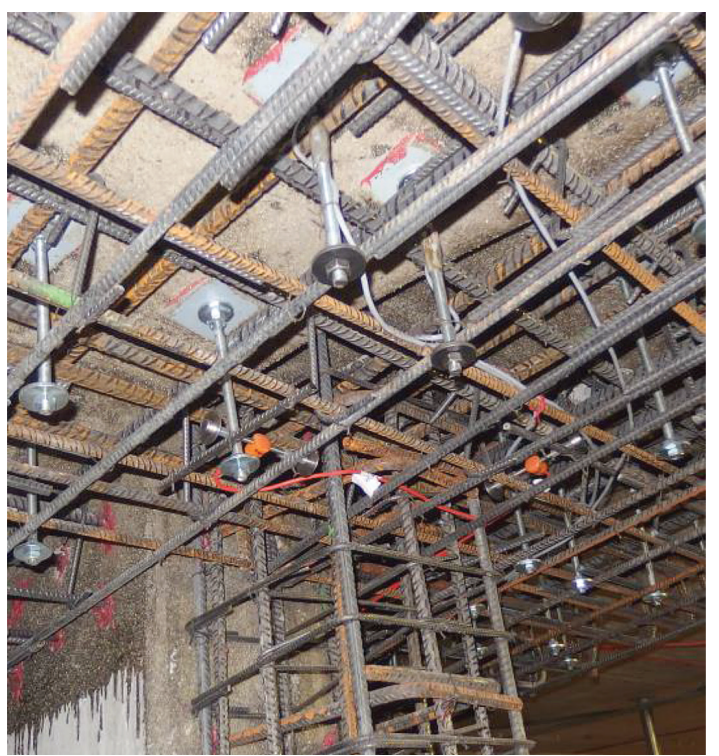

Fig. 13 View of the installed strain gauges in the structure before casting 


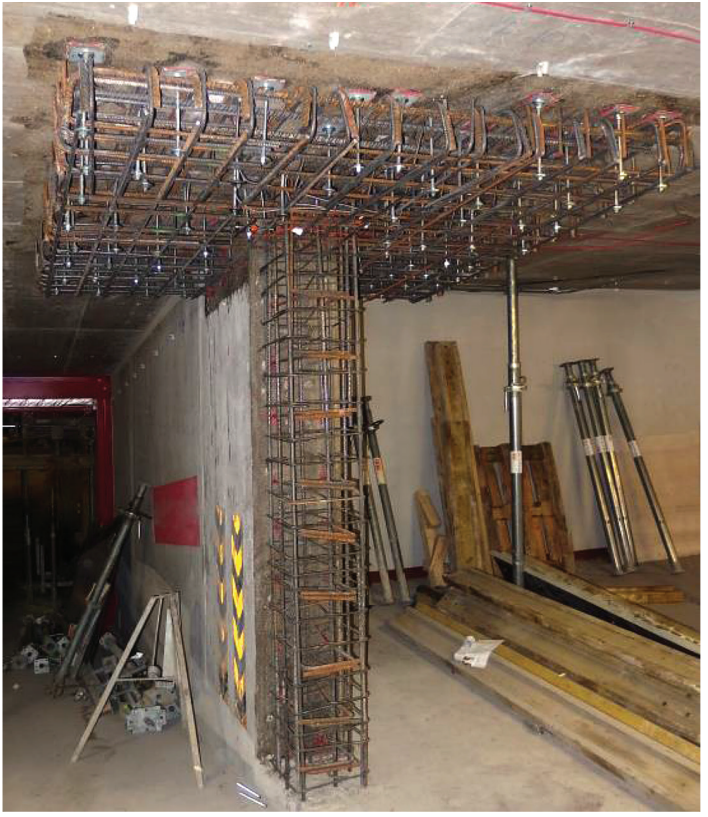

Fig. 14 Completed reinforcement of the additional concrete head and elongation of the wall

teristic cube strength is $39.1 \mathrm{MPa}$. Thus the concrete of the current slab is classified as C30/37.

Demolition work was carried out on the slab before the change in the load on the rehabilitated slab. This work followed the casting of the new structure. The slab was supported in a dense raster by temporary props at a time when a heavy demolition excavator (maximum weight 59.4 t, see Figure 16) was placed above this structure. The measurements were carried out on built-in sensors during the movement of the excavator. The resistance strain gauges showed that they are much more sensitive to this dynamic action than wire strain gauges.

The measurement record for a period of 110 seconds is in Fig. 17, where the limits for both vertical axes are defined as $10 \%$ of the measured variable. The scattering value is $89.4 \mu \mathrm{m} / \mathrm{m}$ for the resistance strain gauge, but the variation coefficient is only $0.8 \%$. For a wire strain gauge, the scattering is $0.154 \mathrm{~Hz}$ and a variation coefficient of $0.04 \%$.

The slab was surveyed by differential levelling prior to the excavator's presence and after the termination of the demolition work and removal of the temporary props. The measurements showed that there was no deviation in the deformations in any part of the slab that would have indicated the presence of new cracks. According to the latest approach for the assessment of the punching capacity (Muttoni, 2008), there is a dependence between the bearing capacity and

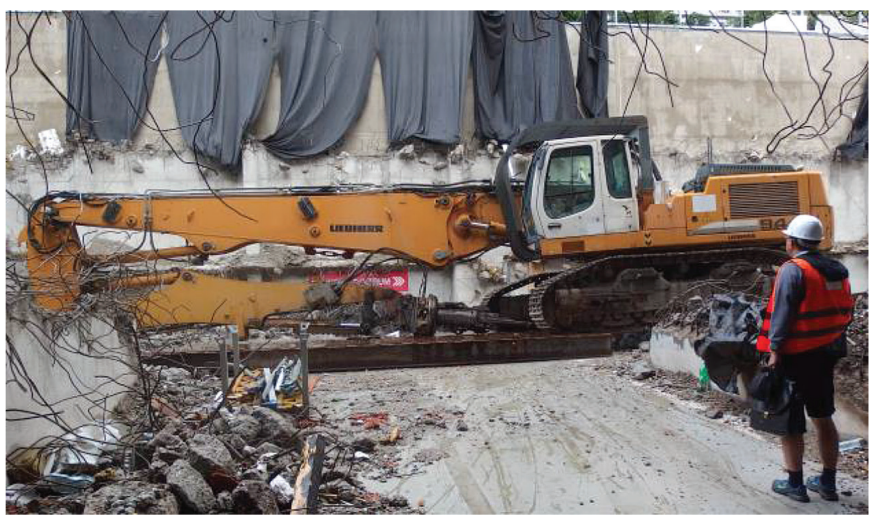

Fig. 16 Maximum load on rehabilitated slab - an excavator with weight of $59.4 t$

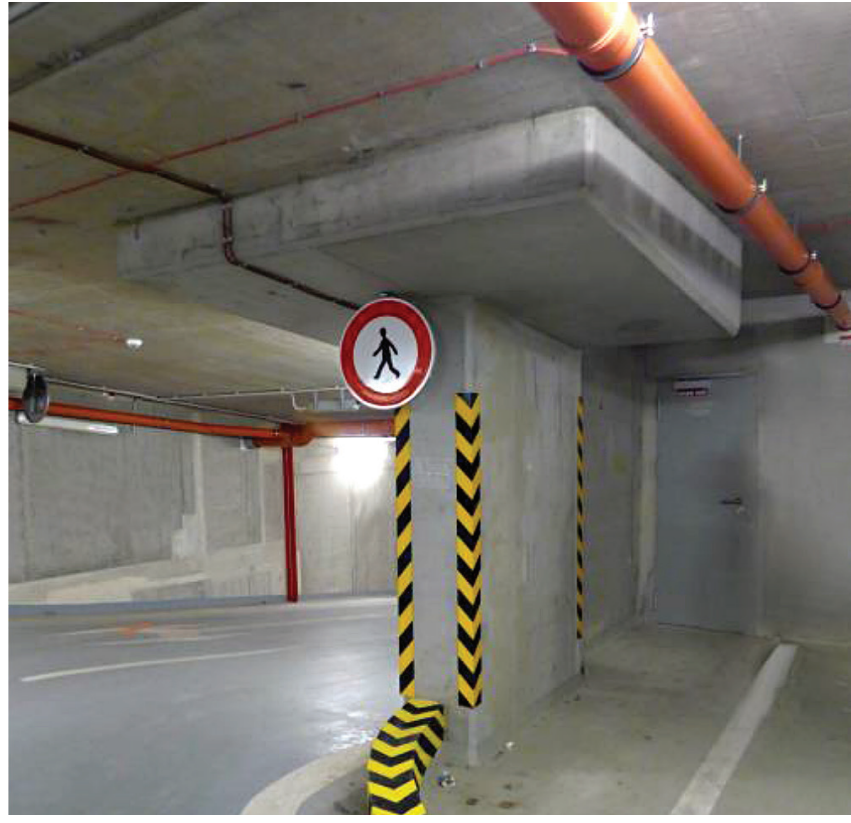

Fig. 15 Final arrangement of the strengthened structure

the rotation of the slab. Therefore, it was possible to state that the construction and demolition work had not affected the load-bearing capacity of the slab-column joint.

In December 2016, a levelling layer of non-structural concrete was placed on the slab for the future roof of the building. The average value of the calculated load was $3.41 \mathrm{kN} / \mathrm{m}^{2}$. Furthermore, the uneven distribution of the load applied was taken into account in the analytical models. The remaining roof layers were completed the following year in December 2017. The value of the load increment calculated for the structure was $6.23 \mathrm{kN} / \mathrm{m}^{2}$. It should be noted that the area of B-C / 10-11 is situated near the lowest point of the roof drainage so that the load values from the superimposed permanent load in the first stage were $2.82 \mathrm{kN} / \mathrm{m}^{2}$ and $8.43 \mathrm{kN} / \mathrm{m}^{2}$ in the second stage. The measurements were initially performed at intervals of 14 days; then the intervals were extended to one month and, for the last two stages, to 4 months.

Fig. 18 shows the values obtained from the resistance strain gauges on the interlocking reinforcement, respectively, the calculated value of the force according to a laboratory-calibrated relationship for each rod. The measurement at the $\mathrm{O} 3$ sensor had already indicated abnormal values in the $3 \mathrm{rd}$ and 4th stages; and the values were out of range after May 2017. Therefore, O3 is excluded from the evaluation.

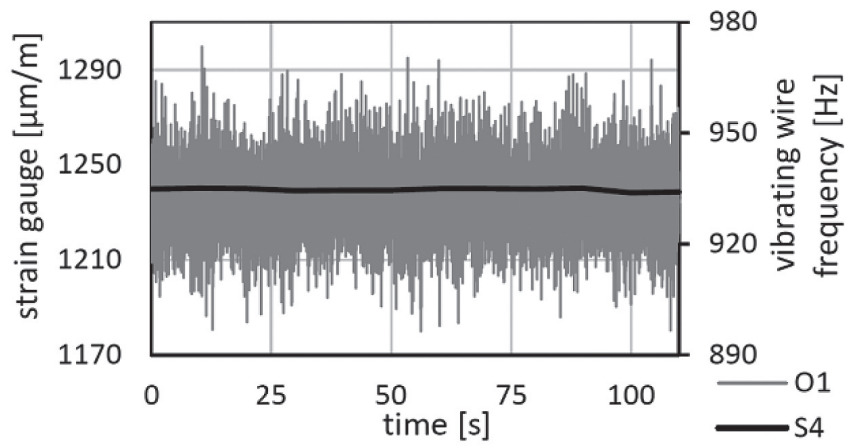

Fig. 17 Measurement record during the period of the excavator's movement 
The $\mathrm{O} 1$ sensor displayed values near the zero force in the rod for the entire measurement period. The $\mathrm{O} 2$ sensor was the only one that recorded an increased force in the rod at the time of the application of the second stage of the dead load.

The last measurement of the resistive strain gauges was performed in May 2018. Unfortunately, all the sensors showed values that were out of range, so they were excluded from the file and are not even displayed.

The vibrating wire strain gauges were expected to capture the strain due to the shrinkage of the new concrete, as described in the previous chapter. In the first 6 months there was an increase in the strain in perpendicular directions with similar values up to $85 \mu \mathrm{m} / \mathrm{m}$, as shown in Fig. 19. Compared to the expected values according to Fig. 3, the shrinkage value should be around $180 \mu \mathrm{m} / \mathrm{m}$. The actual lower shrinkage values could be caused by the concrete mixture used and the complexity of the restrain conditions by the original structure. Until May 2017, the wire strain gauges showed no significant change in the strain, even though the first stage of the superimposed permanent load had been applied. A change in the measured strain occurred during the second stage. It exhibited a steady state of strain upon the completion of the surface layers in December 2017.

\section{COMPARISON WITH THE ANALYTICAL MODELS}

A nonlinear analytical model of part of the affected structure was performed using Atena 3D v5 software to evaluate the data from the experimental measurements. A combination of shell and brick elements for the additional head was used in advance, where the shear failure is decisive. The analytical model, including the displayed finite element mesh, is shown in Fig. 20.
The selected vertical structures had a type of elastic material with concrete parameters, which provided an optimization of the calculation time. The stress in these structures did not exceed the tensile strength of the concrete; therefore, this simplification was possible. The concrete material model was used for the column elements, which were fulfilled by discrete elements of the reinforcement.

The reinforcement was entered into the model according to the documentation for the existing structure; its conformity with the documentation had been verified at several locations. On the bottom surface there was $\varnothing 8 / 150 \mathrm{~mm}-\varnothing 8 / 150 \mathrm{~mm}$ rebar mesh everywhere. Since this reinforcement layout was considered throughout the whole area, it was included in the material model as a smeared reinforcement. The rest of the reinforcement was modelled in a discrete form, Fig. 21.

\subsection{Evaluation of the strain}

The vibrating wire strain gauges were compared with the theoretical values from the analytical model. The effect of the shrinkage in the initial phase was ignored; thus only the load increments in the first and second stage were compared. In the direction of the longer span (B-C), the S4 values from Tab. 3 corresponded very well to the analytical model. Perpendicular to this direction, the S5 sensor in the analytical model predicted only two-thirds of the actually measured strain. This difference is attributed to the vertical tilt of the ramp slab, which was not taken into account in the model. With regard to the fact that they were not laboratory measurements but in-situ measurements at a construction site on an actual structure, it could be described as a good match. The mean material characteristics according to the results on the samples were incorporated in the analytical model.

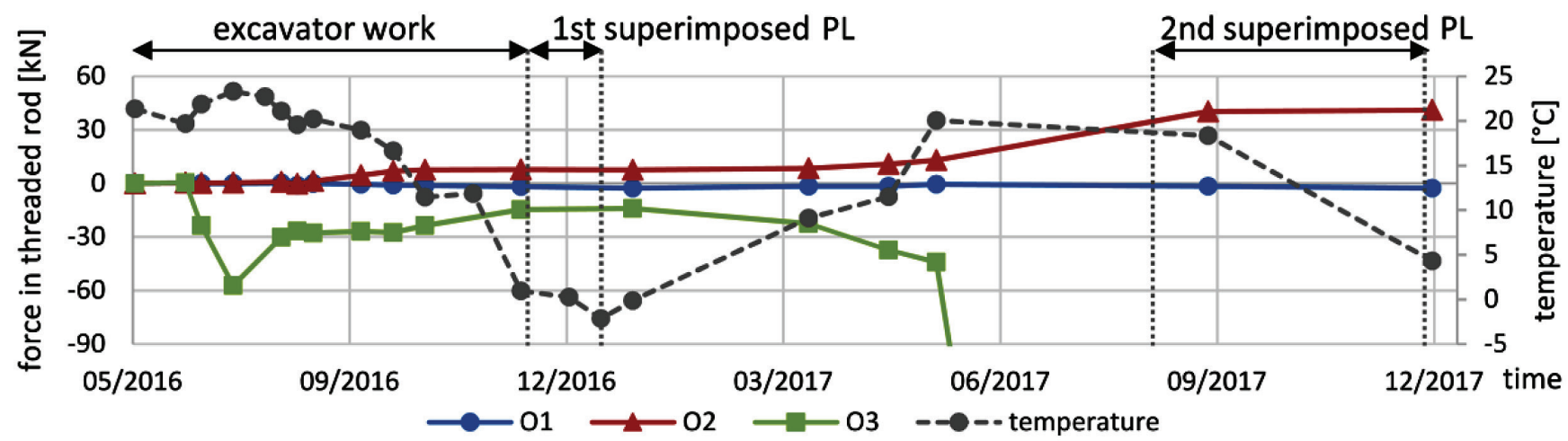

Fig. 18 Measurements performed on the resistance strain gauges

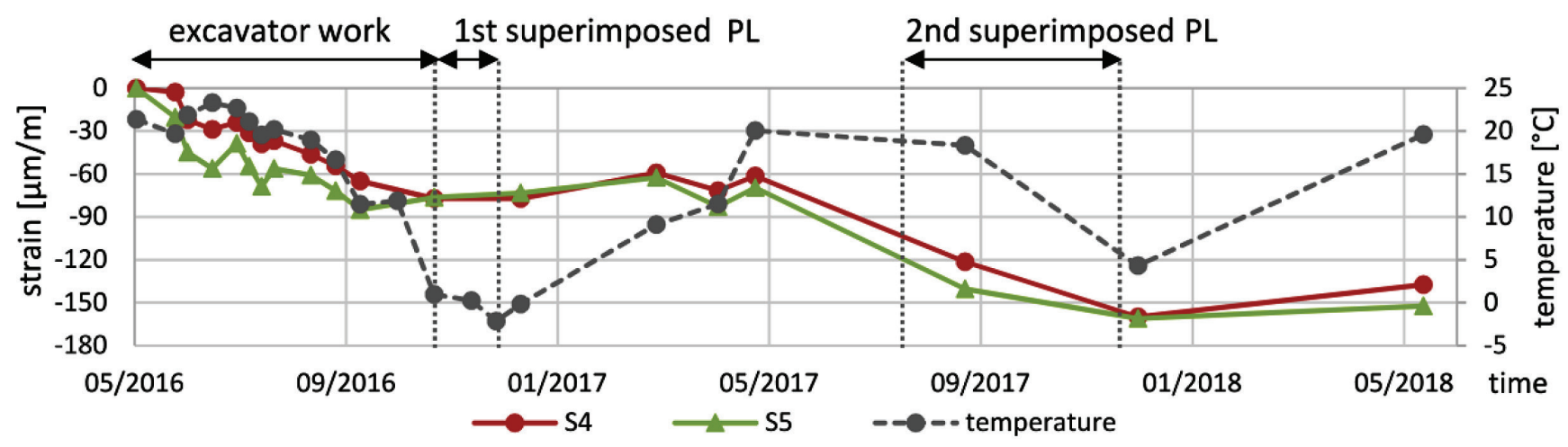

Fig. 19 Measurements performed on the vibrating wire strain gauges 


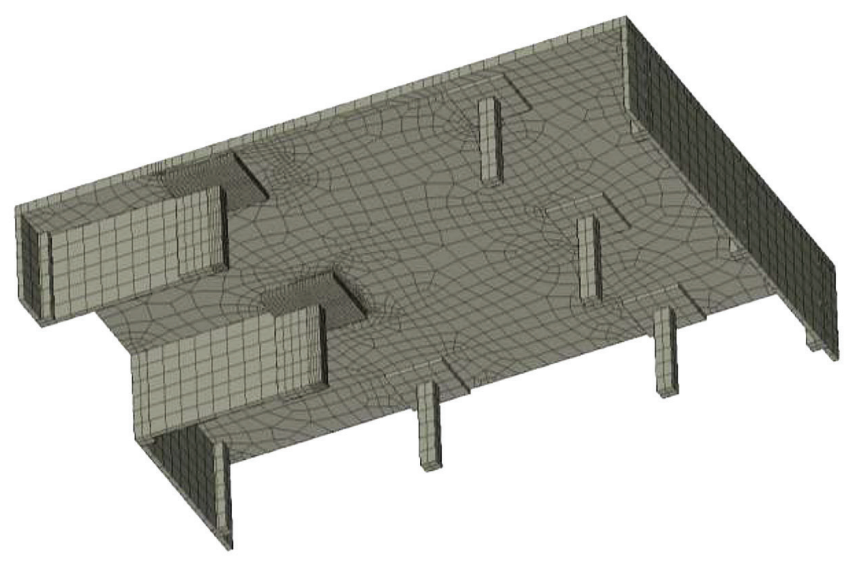

Fig. 20 View of the analytical model structure with mesh

\subsection{Global safety}

The model was slightly modified by the material characteristics and loaded up to the ultimate resistance. An approach according to EN 1992-2 was adopted to determine the safety of the structure; in general, this approach shows the most conservative results of all the methods for assessing design safety (Cervenka, 2008). This approach is also consistent with the Model Code 2010. The original structure was analysed in two variants. The first one is a model for the originally designed strength class of concrete $\mathrm{C} 25 / 30$, while the second model considers the concrete strength class classified on the results of the samples (C30/37). For the rehabilitated structure, two models were also made according to the concrete strength class of the existing structure. The load actions considered are introduced in Tab. 4, where they are supplemented with appropriate partial safety factors. The last column in this table represents the sum of all the design actions considered; it is important for the assessment of the ultimate state.

A comparison of the design load and ultimate resistance obtained from the nonlinear analytical models is shown in Tab. 5. There are pairs of models for the original structure and the strengthened structure. Each of them includes the originally designed concrete class and a class based on the destructively tested samples. The resistance

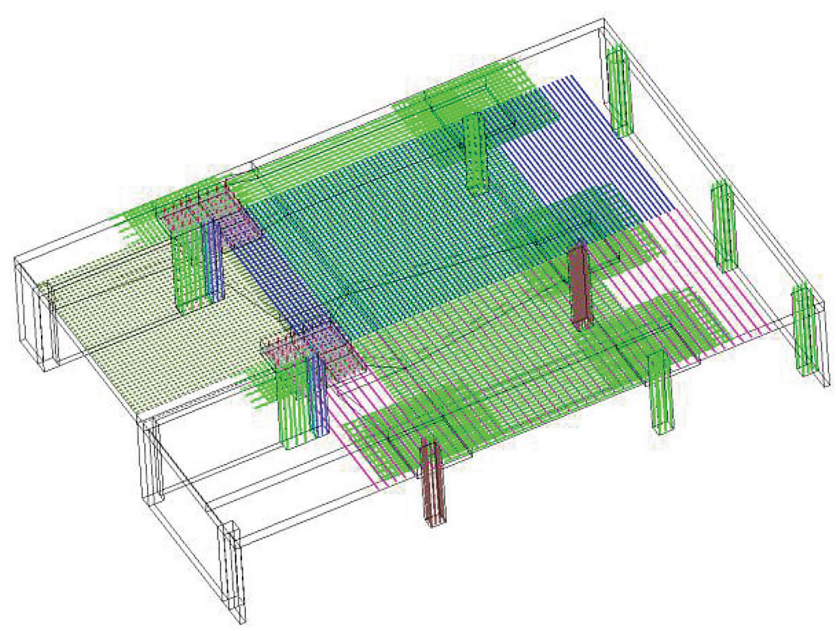

Fig. 21 Discrete reinforcement in the model

Tab. 3 Comparison of the measured values with the analytical model for the increment from the second stage of the superimposed dead load

\begin{tabular}{c|c|c|c}
\hline Sensor & \multicolumn{3}{|c}{$2^{\text {nd }}$ superimposed DL } \\
& $\begin{array}{c}\text { Gauge Strain } \\
{[\mu \mathrm{m} / \mathrm{m}]}\end{array}$ & $\begin{array}{c}\text { Analytical strain } \\
{[\mu \mathrm{m} / \mathrm{m}]}\end{array}$ & $\begin{array}{c}\text { Ratio } \\
\text { Analytical / gauge }\end{array}$ \\
\hline S4 & -88.3 & -87.0 & 0.99 \\
\hline S5 & -78.2 & -51.0 & 0.65 \\
\hline
\end{tabular}

according to EN 1992-2 is obtained from the analytical models upon failure divided by global safety factor 1.27.

The newly rehabilitated structure shows an increase in global load capacity that meets the reliability requirements. The strengthened slab is no longer jeopardised by failure as in the original construction. The governing mode of failure is bending in the place towards the ramp in the strengthened structure. Although the global utilization of the

Tab. 4 Load values, including the partial safety factors for assessment of the design load

\begin{tabular}{c|c|c|c|c|c|c|c}
\hline Variant & Partial factor & $\begin{array}{c}\text { Permanent load } \\
{\left[\mathrm{kN} / \mathrm{m}^{2}\right]}\end{array}$ & Partial factor & $\begin{array}{c}\text { Superimposed } \\
\text { DL } \\
{\left[\mathrm{kN} / \mathrm{m}^{2}\right]}\end{array}$ & Partial factor & $\begin{array}{c}\text { Imposed load } \\
{\left[\mathrm{kN} / \mathrm{m}^{2}\right]}\end{array}$ & $\begin{array}{c}\text { Design load } \\
{\left[\mathrm{kN} / \mathrm{m}^{2}\right]}\end{array}$ \\
\hline original use (garages) & 1.35 & 8.75 & 1.35 & 0.5 & 1.5 & 2.5 & 16.24 \\
\hline proposed use (green roof) & 1.35 & 8.75 & 1.35 & 10.0 & 1.5 & 5.0 & 32.81 \\
\hline
\end{tabular}

Tab. 5 Comparison of the global analytical models according to EN 1992-2

\begin{tabular}{c|c|c|c|c|c|c}
\hline Variant & $\begin{array}{c}\text { Design load } \\
{\left[\mathrm{kN} / \mathrm{m}^{2}\right]}\end{array}$ & $\begin{array}{c}\text { Ultimate load } \\
{\left[\mathrm{kN} / \mathrm{m}^{2}\right]}\end{array}$ & $\begin{array}{c}\text { Global safety } \\
\text { factor } \\
{[-]}\end{array}$ & $\begin{array}{c}\text { Design ultimate } \\
\text { load } \\
\mathrm{EN} \mathrm{1992-2} \\
{\left[\mathrm{kN} / \mathrm{m}^{2}\right]}\end{array}$ & $\begin{array}{c}\text { Utilization } \\
{[-]}\end{array}$ & $\begin{array}{c}\text { Type of failure } \\
\text { original struct. C25/30 }\end{array}$ \\
\hline original struct. C30/37 & 16.24 & 25.50 & 1.27 & 20.08 & 0.81 & punching \\
\hline strengthened struct. C25/30 & 32.81 & 46.24 & 1.27 & 21.57 & 0.75 & punching \\
\hline strengthened struct. C30/37 & 32.81 & 46.95 & 1.27 & 36.97 & 0.90 & bending \\
\hline
\end{tabular}


Tab. 6 Assessment of the structure's punching shear strength according to EN 1992-1-1

\begin{tabular}{c|c|c|c|c|c|c|c|c}
\hline Variant & $\begin{array}{c}\text { Loading area } \\
{\left[\mathrm{m}^{2}\right]}\end{array}$ & $\begin{array}{c}\text { Design load } \\
{\left[\mathrm{kN} / \mathrm{m}^{2}\right]}\end{array}$ & $\begin{array}{c}\text { Design force } \\
{[\mathrm{kN}]}\end{array}$ & $\begin{array}{c}\text { Control } \\
\text { perimeter } \\
{[\mathrm{m}]}\end{array}$ & $\begin{array}{c}\text { Effective } \\
\text { depth } \\
{[\mathrm{m}]}\end{array}$ & $\begin{array}{c}\text { Shear strength } \\
{\left[\mathrm{kN} / \mathrm{m}^{2}\right]}\end{array}$ & $\begin{array}{c}\text { Punching } \\
\text { capacity } \\
{[\mathrm{kN}]}\end{array}$ & $\begin{array}{c}\text { Utilization } \\
{[-]}\end{array}$ \\
\hline original use & 27.6 & 16.24 & 605 & 3.18 & 0.30 & 546 & 520 & 1.16 \\
\hline proposed use & 27.6 & 32.81 & 1162 & 5.52 & 0.55 & 394 & 1196 & 0.97 \\
\hline
\end{tabular}

strengthened structure is slightly higher, there is significant progress in the type of failure. The original structure failed due to punching shear. The failure mode of the rehabilitated slab changed to bending, which is not as brittle as punching and is therefore a safer solution.

It should be noted that the design and implementation of the additional concrete head was carried out before compiling the global nonlinear model. The effects were investigated separately.

\subsection{Local safety}

The complementary approach based on manual calculations were made for the assessment of punching shear at the end of wall $\mathrm{C} / 10$ in accordance with EN 1992-1-1. A standard approach for the wall end and concrete strength class $\mathrm{C} 30 / 37$ was adopted. The loading area was determined based on the development of zero isoline for the shear slab force. The area runs behind the wall end at the distance $1.5 d$, which is also the limiting value for determination of the control perimeter. All the governing inputs and outputs are summed up in Tab. 6. The design force is counted from the loading area and the design force applied, which was multiplied by $\beta=1.35$. The punching capacity is set up as a multiple of the effective depth, the control perimeter, and the shear strength.

The proposed use exhibits the wall end by a noticeably higher design force, which is $223 \%$ of the capacity of the original structure. The simplified design approach shows that the original structure would not have fulfilled the requirements of EN 1992-1-1, but the global safety approach proves the safety of the original structure for the old loading scheme. The manual calculations for proposed use indicate the necessity for the structural strengthening against punching shear at the wall end.

\section{CONCLUSION}

An analysis of the impact of shrinkage on an additionally cast head and the effect of the slip-bond of the reinforcement was performed. It was shown that for a sufficiently fine mesh, the bond-slip effect may be ignored. For normal shrinking values, there is no slip at the interface between the slab and the head. In practice, a concrete mixture with minimal shrinkage is used for such special applications. For modelling the absolute bearing capacity in punching, these phenomena can be ignored.

The findings from the research were applied to the design of the concrete head. The proposed rehabilitation was deliberately more robust, and the final structure had a different type of failure while maintaining the same global safety. The measurements on the vibrating wire strain gauges showed good agreement with the analytical model The resistance strain gauges on the rods had less of a matching value, since at normal load values there is no significant development of cracks inside the head, so the data had a complicated interpretation; even these sensors showed low stability in the long-term measurements. The changes in temperature of the concrete structure had a significant effect on the measurements by the resistance strain gauges too. At the same time, it should be noted that almost 2 years after the casting of the head, the vibrating wire strain gauges were still in a functioning condition, but the resistance strain gauges no longer worked.

Using an example of an actual structure, an appropriate proposal for an additionally cast concrete head, which conforms with a theoretical approach, was shown.

It should be noted that the implementation of the long-term measurements in an actual situation at a construction site is very complicated compared to laboratory conditions. This issue should be a part of future research.

\section{Acknowledgements}

This paper was made possible through support from the TH03020446 project (Technology Agency of the Czech Republic) and FAST-J-16-3817 (Faculty of Civil Engineering, Brno University of Technology). 


\section{REFERENCES}

Belletti, B. - Pimentel, M. - Scolari, M. - Walraven, J. C. (2015) Safety assessment of punching shear failure according to the level of approximation approach. Structural Concrete, Vol.16, No. 3, pp. 366-380.

Bigaj, A. (1999) Structural Dependence of Rotational Capacity of Plastic Hinges in RC Beams and Slabs (PhD Thesis), TU Delft, The Netherlands.

CEN. (2002) Eurocode: Basis of structural design. Brussels, Belgium.

CEN. (2004) Eurocode 2: Design of Concrete Structures - Part 1-1: General Rules and Rules for Buildings. Brussels, Belgium.

CEN. (2005) Eurocode 2: Design of concrete structures - Part 2: Concrete bridges - Design and detailing rules. Brussels, Belgium.

Cervenka, V. (2008) Global Safety Format for Nonlinear Calculation of Reinforced Concrete. Beton Und Stahlbetonbau, Vol. 103, No. S1, pp. 37-42.

Červenka, V. - Jendele, L. - Červenka, J. (2018) ATENA Program Documentation: Part 1-Theory. Available at: https://www.cervenka.cz/assets/files/atena-pdf/ATENA_Theory.pdf (accessed 17/06/2018).
Esfahani, M. R. - Kianoush, M. R. - Moradi, A. R. (2009). Punching shear strength of interior slab-column connections strengthened with carbon fibre reinforced polymer sheets. Engineering Structures, Vol. 31, No. 7, pp. 1535-1542.

fib. (2013) Model Code for Concrete Structures 2010. Print ISBN: 978-3-433-03061-5

Muttoni, A. (2008) Punching shear strength of reinforced concrete slabs without transverse reinforcement. ACI Structural Journal, Vol. 105, No. 4, pp. 440-450.

Nováček, J. - Zich, M. (2016) Study of Strengthening Flat Slabs against Punching by Additional Column Heads. Key Engineering Materials, Vol. 691, pp. 321-332.

Polak, M. A. - Bu, W. (2013) Design Considerations for Shear Bolts in Punching Shear Retrofit of Reinforced Concrete Slabs. ACI Structural Journal, Vol. 110, No. 1, pp. 15-26.

Pryl, D. - Červenka, J. (2018) ATENA Program Documentation: Part 11 - Troubleshooting Manual. Available at: https://www. cervenka.cz/assets/files/atena-pdf/ATENA-Troubleshooting.pdf, (accessed 17/06/2018). 